\title{
Urea and Oxidative Stress in Type 2 Diabetes
}

\section{Afsaneh Morteza, Yaser Jenab, Arash Aghajani Nargesi, Zaniar Ghazizadeh, Mirataollah Salabati, Alireza Esteghamati and Manouchehr} Nakhjavani*

Endocrinology and Metabolism Research Center (EMRC), Vali-Asr Hospital, Tehran University of Medical Sciences, Tehran, Iran

\begin{abstract}
Introduction : Studies have shown altered protein metabolism in the presence of excess carbohydrate such as type 2 diabetes (T2DM). Protein metabolism is impaired in T2DM as a result of oxidative stress and insulin resistance. Here we aimed to study the correlation of serum urea as an indicator of protein metabolism with malondialdehyde (MDA) and superoxide dismutase (SOD), as indicators of oxidative stress in T2DM patients.
\end{abstract}

Methods : We performed a cross sectional study on 151 patients with T2DM and 45 healthy controls. We quantified fasting blood sugar (FBS), HbA1C, lipid profile, urea, MDA and SOD in the studied groups.

Results : Patients had a higher serum urea, FBS, HbA1C, triglyceride, cholesterol, LDL, MDA and SOD than controls. GFR and serum HDL levels were lower in patients. Diabetic men had a lower HDL and a higher albuminuria compared to diabetic women. There were no difference in any of the studied variables between men and women in control group. Serum urea levels were negatively correlated with MDA $(r=-0.70, p<0.01)$ and SOD $(r=-0.60$, $\mathrm{p}<0.01)$ in men with type 2 diabetes. This was significant after multiple adjustments for HbA1C, GFR, albuminuria and duration of diabetes.

Discussion : We showed the negative correlation of serum urea levels with the markers of oxidative stress in T2DM men. It could be concluded that protein metabolism and urea formation is more severely influenced in diabetic men. This explains the negative correlation of urea with MDA and SOD, only in men with T2DM.

Keywords: MDA; SOD; Urea; Type 2 diabetes; Oxidative stress; Gender difference.

\section{Introduction}

In about 2000 years ago, Aretaeus the capudocian, the Greek physician, described diabetes as a condition with a "melting down of the flesh and limb into urine" [1]. With reference to type 1 diabetes, this is remarkably amazingly accurate observation. In type 2 diabetes reports have been inconsistent, that protein metabolism has been reported to be both unaffected and affected [2,3]. In 1993," insulin resistance of protein metabolism", was firstly introduced in patients with type 2 diabetes [4,5]. It is defined as the defect in amino acid metabolism and suppression of protein breakdown which is correlated with insulin resistance [6]. Since then many studies have shown a negative nitrogen balance and loss of nitrogen from most organs in patients with type 2 diabetes $[7,8]$. Protein malnutrition is associated with an increased level of oxidative stress [9]. Protein restriction in rats with type 2 diabetes, cause an accelerated oxidative stress [10,11]. Children with kwashiorkor have a higher level of lipid preoxidation [12-14]. Consistently protein malnutrition in intra uterine growth retardation pregnancies is the leading cause of oxidative stress in these patients $[15,16]$. Insulin resistance of protein metabolism could be impaired as one of the causes of protein malnutriton [17]. It often precedes the onset of type 2 diabetes by many years. Studies have shown the role of insulin resistance in the induction of reactive oxygen species (ROS) and oxidative stress in type 2 diabetes [17-19]. Oxidative stress is a disturbance in the pro-oxidant, anti-oxidant balance in favor of the former, which leads to the potential damage [20]. Superoxide dismutases (SOD) are a class of enzymes that catalyze the dismutation of superoxide into oxygen and hydrogen peroxide. SOD levels are increased in the situations of oxidative stress [21]. Malondialdehyde (MDA) is the organic compound considered as a reactive species which occurs naturally and is a marker for oxidative stress [22]. Superoxide results into macromolecules alteration such as polyunsaturated fatty acids in membrane lipids. This results into the generation of MDA [22]. Both MDA and SOD are increased in patients with type 2 diabetes, due to increased oxidative stress [23].

Here we aimed to study the correlation of serum urea as an indicator of protein metabolism with MDA and SOD as markers of oxidative stress in patients with type 2 diabetes.

\section{Methods}

We performed a cross sectional study on 151 patients with type 2 diabetes from the diabetes clinic of Vali Asr hospital affiliated with Tehran University of Medical Science plus 45 controls. Diabetes was diagnosed according to the criteria of the American Diabetes Association which is based on glycemia [24]. Exclusion criteria were smoking, pregnancy, creatinine $>1.5 \mathrm{mg} / \mathrm{dl}$ or GFR $<70 \mathrm{cc} / \mathrm{min}$, glomerulonephritis, thyroid disorders, acute infections, stroke, diabetic ketoacidosis, non-ketonic hyperosmolar diabetes, congestive heart failure, use of antioxidant and hospital admission in recent 6 months. None of the participants were on hormone replacement therapy. Controls were healthy volunteers from the patients' concomitants or hospital staffs. Healthy controls were selected from those without any known disease including type 2 diabetes, hyperlipidemia, ischemic heart disease and malignancy. Demographic and anthropometric data including age, sex, duration of diabetes, height and weight in light clothing and blood pressure in sitting position were recorded. Blood pressure was re measured twice after 5 minutes average. The body mass index (BMI; $\mathrm{Kg} / \mathrm{m}^{2}$ ) was calculated according to the Quetelet formula.

Diet was almost similar in composition in all the studied groups.

Corresponding author: Manouchehr Nakhjavani, MD, Professor of Endocrinology Endocrinology and Metabolism Research Center (EMRC), Vali-Asr Hospital, Tehran University of Medical Sciences, Tehran, P.O. Box: 13145-784, Iran, Tel: (+9821)-8841791; Fax: (+9821)-64432466; E-mail: nakhjavanim@tums.ac.ir

Received October 25, 2011; Accepted March 07, 2012; Published March 15 2012

Citation: Morteza A, Jenab Y, Nargesi AA, Ghazizadeh Z, Salabati M, et al. (2012) Urea and Oxidative Stress in Type 2 Diabetes. J Metabolic Synd 1:105. doi:10.4172/2167-0943.1000105

Copyright: (C 2012 Morteza, et al. This is an open-access article distributed under the terms of the Creative Commons Attribution License, which permits unrestricted use, distribution, and reproduction in any medium, provided the original author and source are credited. 
Patients and controls were instructed to consume standardized meals that contained $50 \%$ carbohydrates, $30 \%$ fat and $20 \%$ protein, for two weeks before the beginning of the study. All the patients were consulted by a nutritionist during the study. The glomerular filtration rate (GFR) was calculated using the Cockcroft-Gault formula [25]. All participants gave written informed consent before participation. The research was carried out according to the principles of the declaration of Helsinki; the local ethics review committee of Tehran University of Medical Science approved the study protocol.

\section{Blood Samples}

Blood samples were collected after 12 hours of fasting were centrifuged and kept at $-70^{\circ} \mathrm{C}$ until analysis. Glucose measurements (intra-assay coefficient of variants [CV] 2.1\%, inter-assay CV 2.6\%) were carried out using the glucose oxidase method. Cholesterol, high density lipoprotein cholesterol (HDL-C), low density lipoprotein cholesterol (LDL-C) and triglycerides were determined using direct enzymatic methods (Parsazmun, Karaj, Iran). Urea was measured using colorimetric assay (Parsazmoon, Karaj, Iran). Creatinine was measured using calibrated Jaffe method (Parsazmoon, Karaj, Iran). Patients were instructed in the collection of timed 24-hour urine for measurement of urinary albumin excretion and were told to return on the morning after the end of the urine collection. Women were not examined during menstruation. All specimens were confirmed to be sterile by culture. Urinary albumin was measured by immunoturbidometry (DAKO, Denmark) in duplicate and the average of the 2 measurements was used for the analysis. Serum EC-SOD was assayed using a 2-step ELISA with a monoclonal antibody using the Cayman Chemical SOD assay kit (Cayman Chemicals, Ann Arbor,MI, USA). One unit of SOD is defined as the amount of enzyme needed to exhibit 50\% dismutation of the superoxide radical. Serum MDA levels were measured using the colorimetric method. After reaction of thiobarbituric acid with MDA, the reaction product was extracted in butanol. Separation of the organic phase was facilitated by centrifugation at 3,000 rpm for 10 minutes and its absorbance was determined spectrometrically at $530 \mathrm{~nm}$ (Cayman Chemicals, Ann Arbor, MI, USA).

\begin{tabular}{|l|l|l|l|}
\hline & $\begin{array}{l}\text { Patients with type } \\
\text { 2 diabetes }(\mathbf{n}=151)\end{array}$ & $\begin{array}{l}\text { Healthy con- } \\
\text { trols }(\mathbf{n = 4 5})\end{array}$ & P value \\
\hline Age (yrs) & $58.9 \pm 0.7$ & $59.0 \pm 1.0$ & $\mathrm{NS}$ \\
\hline Female (n, \%) & $80(52 \%)$ & $40(44 \%)$ & $\mathrm{NS}$ \\
\hline BMI(kg/m2) & $27.04 \pm 0.4$ & $27.2 \pm 0.4$ & $\mathrm{NS}$ \\
\hline Systolic blood pressure (mmHg) & $143.5 \pm 6.7$ & $125.2 \pm 1.5$ & $\mathrm{NS}$ \\
\hline $\begin{array}{l}\text { Diastolic blood pressure } \\
\text { (mmHg) }\end{array}$ & $84.3 \pm 0.8$ & $78.4 \pm 1.2$ & $<0.001$ \\
\hline Urea (mg/dl) & $50.2 \pm 1.9$ & $27.5 \pm 1.3$ & $<0.001$ \\
\hline Fasting Blood Sugar (mg/dl) & $173.7 \pm 5.0$ & $88.6 \pm 1.0$ & $<0.001$ \\
\hline HbA1C (\%) & $8.8 \pm 0.2$ & $4.8 \pm 0.1$ & $<0.001$ \\
\hline Triglyceride (mg/dl) & $191.8 \pm 6.4$ & $105.7 \pm 5.5$ & $<0.001$ \\
\hline Cholesterol (mg/dl) & $194.4 \pm 4.1$ & $205.4 \pm 3.4$ & $<0.001$ \\
\hline LDL-C (mg/dl) & $88.8 \pm 2.2$ & $113.2 \pm 1.7$ & $<0.001$ \\
\hline HDL-C (mg/dl) & $31.7 \pm 0.5$ & $52.0 \pm 1.6$ & $<0.001$ \\
\hline MDA ( $\boldsymbol{\mu m o l / L )}$ & $3.67 \pm 0.09$ & $2.47 \pm 0.13$ & $<0.001$ \\
\hline SOD (U/ml) & $84.1 \pm 1.6$ & $70.4 \pm 0.9$ & $<0.001$ \\
\hline GFR (ml/min) & $73.0 \pm 1.9$ & $89.2 \pm 2.7$ & $<0.001$ \\
\hline Log-albuminuria (mg/day) & $2.006 \pm 0.079$ & - & - \\
\hline
\end{tabular}

Variables are expressed as mean \pm standard error of mean (SEM). The column of "P value" is presented when comparing patients with type 2 diabetes and controls.

Table 1: The primary characteristics of patients with type 2 diabetes and controls.

\begin{tabular}{|c|c|c|c|c|}
\hline & \multicolumn{2}{|c|}{ Patients with type 2 diabetes } & \multicolumn{2}{|c|}{ Healthy Controls } \\
\hline & $\operatorname{Men}(n=71)$ & Women $(n=80)$ & Men $(n=20)$ & Women $(n=25)$ \\
\hline Age (yrs) & $60.4 \pm 1.04$ & $59.4 \pm 0.8$ & $59.6 \pm 1.72$ & $58.5 \pm 1.25$ \\
\hline Urea (mg/dl) & $50.3 \pm 2.3$ & $50.1 \pm 2.8$ & $30.2 \pm 2.7$ & $26.7 \pm 1.4$ \\
\hline HbA1C (\%) & $8.9 \pm 0.2$ & $8.7 \pm 0.1$ & $4.8 \pm 0.1$ & $4.9 \pm 0.1$ \\
\hline $\begin{array}{l}\text { Fasting Blood } \\
\text { Sugar (mg/dl) }\end{array}$ & $174.2 \pm 6.6$ & $173.2 \pm 7.4$ & $89.2 \pm 1.8$ & $88.2 \pm 1.2$ \\
\hline $\begin{array}{l}\text { Triglyceride } \\
\text { (mg/dl) }\end{array}$ & $188.3 \pm 8.0$ & $194.8 \pm 9.7$ & $101.5 \pm 7.3$ & $109.0 \pm 8.1$ \\
\hline $\begin{array}{l}\text { Cholesterol } \\
\text { (mg/dl) }\end{array}$ & $195.1 \pm 6.0$ & $193.7 \pm 5.5$ & $204.3 \pm 4.5$ & $206.3 \pm 4.9$ \\
\hline LDL-C (mg/dl) & $89.9 \pm 3.1$ & $87.8 \pm 3.2$ & $117.3 \pm 1.7$ & $109.9 \pm 2.6$ \\
\hline HDL-C (mg/dl) & $30.7 \pm 0.6^{*}$ & $32.7 \pm 0.7$ & $49.0 \pm 2.1$ & $54.3 \pm 2.3$ \\
\hline MDA ( $\mu \mathrm{mol} / \mathrm{L})$ & $3.8 \pm 0.09$ & $3.6 \pm 0.12$ & $2.52 \pm 0.19$ & $2.48 \pm 0.17$ \\
\hline SOD (U/ml) & $88.7 \pm 2.2$ & $79.9 \pm 3.9$ & $71.3 \pm 1.9$ & $69.5 \pm 2.01$ \\
\hline GFR (ml/min) & $75.8 \pm 2.4$ & $70.6 \pm 2.6$ & $93.3 \pm 4.4$ & $85.9 \pm 3.4$ \\
\hline $\begin{array}{l}\text { Log-albumin- } \\
\text { uria (mg/day) }\end{array}$ & $2.24 \pm 0.109^{* *}$ & $1.87 \pm 0.109$ & - & - \\
\hline
\end{tabular}

Variables are expressed as mean \pm standard error of mean (SEM). ${ }^{*} \mathrm{p}<0.05$; ** $\mathrm{p}<0.01 ;{ }^{* * *} \mathrm{p}<0.001$, when comparing men and women in diabetes and control groups

Table 2: Characteristics of the patients in the studied groups stratified according to gender.

\section{Statistical Analysis}

The statistical package SPSS 17 for windows (Chicago, Illinois, USA), was used for analysis. Variables distributed normally are presented as mean and standard error of mean (SEM). Amount of albuminuria was log-transformed and employed for further analysis. Independent sample test was used to compare variables between patients and controls as well as between men and women. Pearson's correlation test was employed to test the correlation of serum urea with other studied variables. Partial correlation was employed to test the correlation of urea with MDA and SOD after multiple adjustments for GFR, $\mathrm{HbA1C}$, albuminuria and duration of diabetes.

\section{Results}

Characteristics of the patients and controls are presented in Table 1. The frequency of insulin therapy was $(30 / 151 ; 20 \%)$ and the frequency of statin therapy was $(70 / 151 ; 46 \%)$ in patients with type 2 diabetes. Patients had a higher serum urea, FBS, HbA1C, triglyceride, cholesterol, LDL, SOD, MDA and a lower HDL than controls (Table 1).We then stratified the studied groups according to gender. Diabetic men had a lower HDL and a higher albuminuria compared to diabetic women. There were no difference in any of the studied variables between men and women in control group (Table 2).

Serum urea levels were negatively correlated with MDA $(r=-0.70$, $\mathrm{p}<0.01)$ and SOD $(\mathrm{r}=-0.60, \mathrm{p}<0.01)$ in men with type 2 diabetes (Figure 1 ), when there was not such a significant correlation among women and controls (Table 3). This was significant after multiple adjustments for HbA1C, GFR, albuminuria and duration of diabetes (MDA: $r=-0.72$, $p<0.001$; SOD: $r=-0.59 ; p<0.001)$ using partial correlation. Serum urea levels were not correlated with any of the studied variables in men and women in the controls group (Table 3).

\section{Discussion}

Oxidative stress is the hallmark of type 2 diabetes. It precedes diabetes years before the diagnosis of diabetes and is also the culprit mechanism of disease such as metabolic syndrome or insulin resistance. Urea is one of the main indicators of protein metabolism and nitrogen balance in humans [26], which is recently found to have 
some association with the markers of oxidative stress [27,28]. We also performed another study and consistent with the current findings, showed that urea is negatively correlated with the makers of metabolic syndrome such as LCAT enzyme (unpublished paper). This is the first report demonstrating the negative correlation of serum urea levels with markers of oxidative stress including MDA and SOD in men with type 2 diabetes. This was significant after multiple adjustments for HbAlc, GFR, albuminuria and duration of diabetes.

Mitochondria, described as a cellular power plants, are the site of reaction of oxidative phosphorylation in electron transport chain, which results in the formation of ATP $[29,30]$. In the situation of hyperglycemia the voltage across the mitochondrial membrane increases above the critical threshold for superoxide production. This will induce the production of reactive oxygen species [31]. Urea genesis is a biochemical cycle in the liver initiated in the mitochondria and completed in the cytosole [32]. The effect of mitochondirial hyperactivity with glucose oxidation on hepatic urea genesis has not been examined. Amino acids ingested from the foods which are not used for the synthesis of proteins are oxidized [33]. The oxidation pathway starts with transamination, the removal of the amino group by a transaminase [33]. All amino nitrogen from amino acid that undergoes transamination, are concentrated in L-Glutamate [32,33]. This is important because L-Glutamate is the only amino acid that undergoes oxidative deamination (release of ammonia) [33]. Release of ammonia from glutamate is then catalyzed by the hepatic L-Glutamate dehydrogenase (GDH), which is located in the mitochondria of the liver tissue [33]. GDH is allosterically inhibited by ATP, GTP and NADH and is activated by $\mathrm{ADP}[32,34]$. Under the situation of caloric restriction and low blood glucose, the activity of GDH is raised in order to increase the amount of energy $[33,35]$. In diabetic cells with high glucose inside, there is more glucose being oxidized which in effect pushes more

\begin{tabular}{|c|c|c|c|}
\hline & & SOD $(\mathbf{U} / \mathbf{m l})$ & MDA $(\boldsymbol{\mu m o l} / \mathbf{L})$ \\
\hline \multirow{3}{*}{ Urea $(\mathbf{m g} / \mathbf{d l})$} & Women with type 2 diabetes & -0.02 & -0.01 \\
\cline { 2 - 4 } & Men with type 2 diabetes & $-\mathbf{0 . 6 0 * * *}$ & $\mathbf{- 0 . 7 0 ^ { * * * }}$ \\
\cline { 2 - 4 } & Women in control Group & -0.03 & -0.37 \\
\cline { 2 - 4 } & Men in control group & 0.23 & -0.05 \\
\hline
\end{tabular}

${ }^{*} p<0.05 ;{ }^{* *} p<0.01$

Table 3: Presenting the partial correlation coefficient $(r)$ of serum urea with MDA and SOD in diabetic men, diabetic women, men and women in control group. electron donors into electron transport chain [36]. This results into the production of free radical hydrogen peroxide, superoxide and a decreased NAD/NADH ratio [36]. Under normal conditions, ROS are cleared from the cell by the action of SOD, catalase, or glutathione peroxidase. The main damage to cells results from the ROS-induced alteration of macromolecules such as polyunsaturated fatty acids in membrane lipids, which results into the generation of MDA. Moreover SOD increases to protect cells against oxidative damage. Urea genesis decreases in hyperglycemia. This may explain the negative correlation between serum urea and markers of oxidative stress such as MDA, SOD in patients with type 2 diabetes (Figure 2).

In consistent with our findings, Dasarathy and collaborators showed that intralipid infusion in patients with non alcoholic steato hepatitis (NASH) increases plasma glutathione levels. Because plasma glutathione is mostly derived from the liver, this increase is a result of elevated oxidative stress caused by higher fatty acid oxidation in subjects with NASH. Likewise, intralipid infusion decreased urea genesis in these patients. They concluded that increased level of hepatic $\beta$-oxidation is associated with a decreased level of ureagenesis [37]. Interestingly Anderson et al, showed that the mitochondria in the arterial tissue of type 2 diabetes show a sharply decreased capacity of glutamate metabolism compared to non diabetic subjects [38]. It is shown that there is a reduced mitochondrial protein metabolism in patients with type 2 diabetes $[39,40]$.

Why the negative correlation between serum urea and markers of oxidative stress is only observed in men with type 2 diabetes? We do not have a definite answer to this question, but previous studies have postulated a number of theories. Chevalier et al. showed sex difference on protein anabolic actions of insulin which is significantly greater in men [41]. Consistently Gougeon et al. showed that the kinetics of whole body proteins is elevated in hyperglycemic men. There is an insulin resistance protein metabolism in diabetic men, when this would not happen in diabetic women [2,42]. Pereira et al. [43] reported the results from an extensive study which defined whole-body protein metabolism in patients with type 2 diabetes. The study was designed to evaluate the basal, postabsorptive and insulin-stimulated amino acid and glucose metabolism, using infusion of labeled leucine in patients with type 2 diabetes and healthy controls. They showed that despite a similar basal whole-body leucine fluxes between patients and controls, total leucine
A:

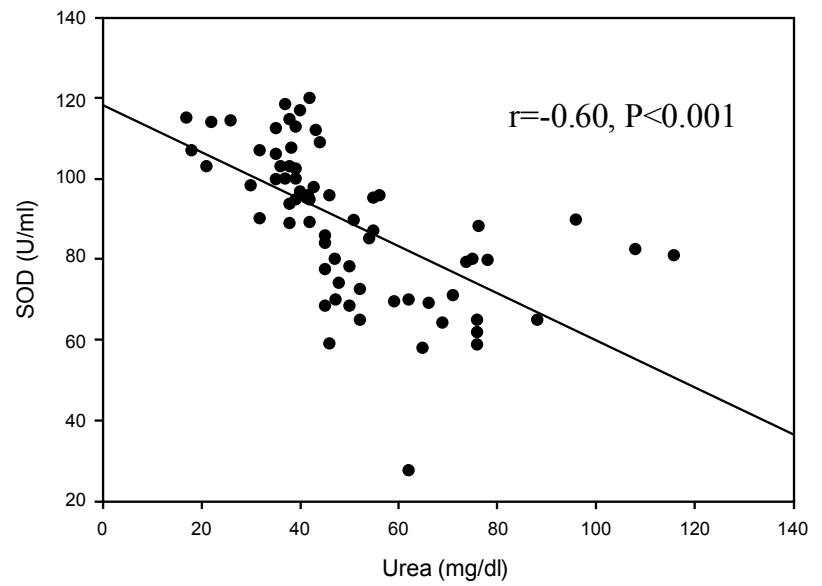

B:

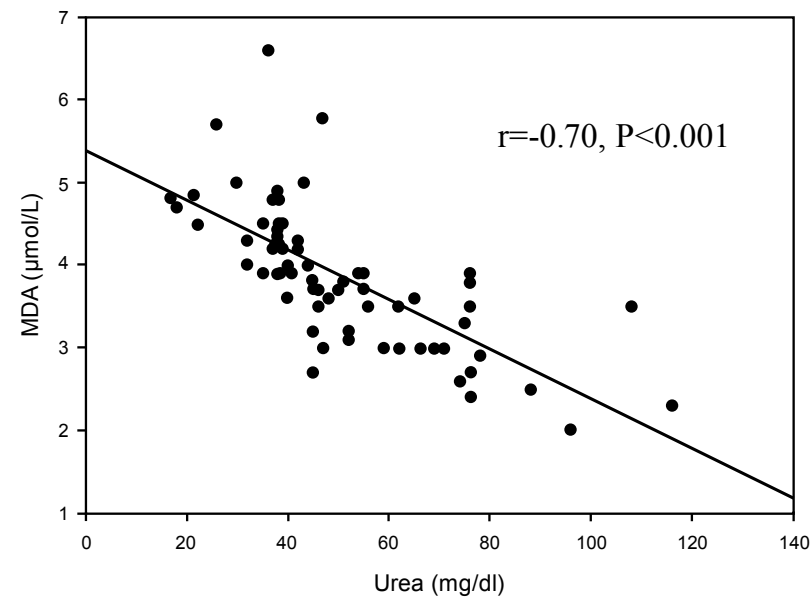

Figure 1: The correlation of Urea with A: SOD and B: MDA in men with type 2 diabetes. 


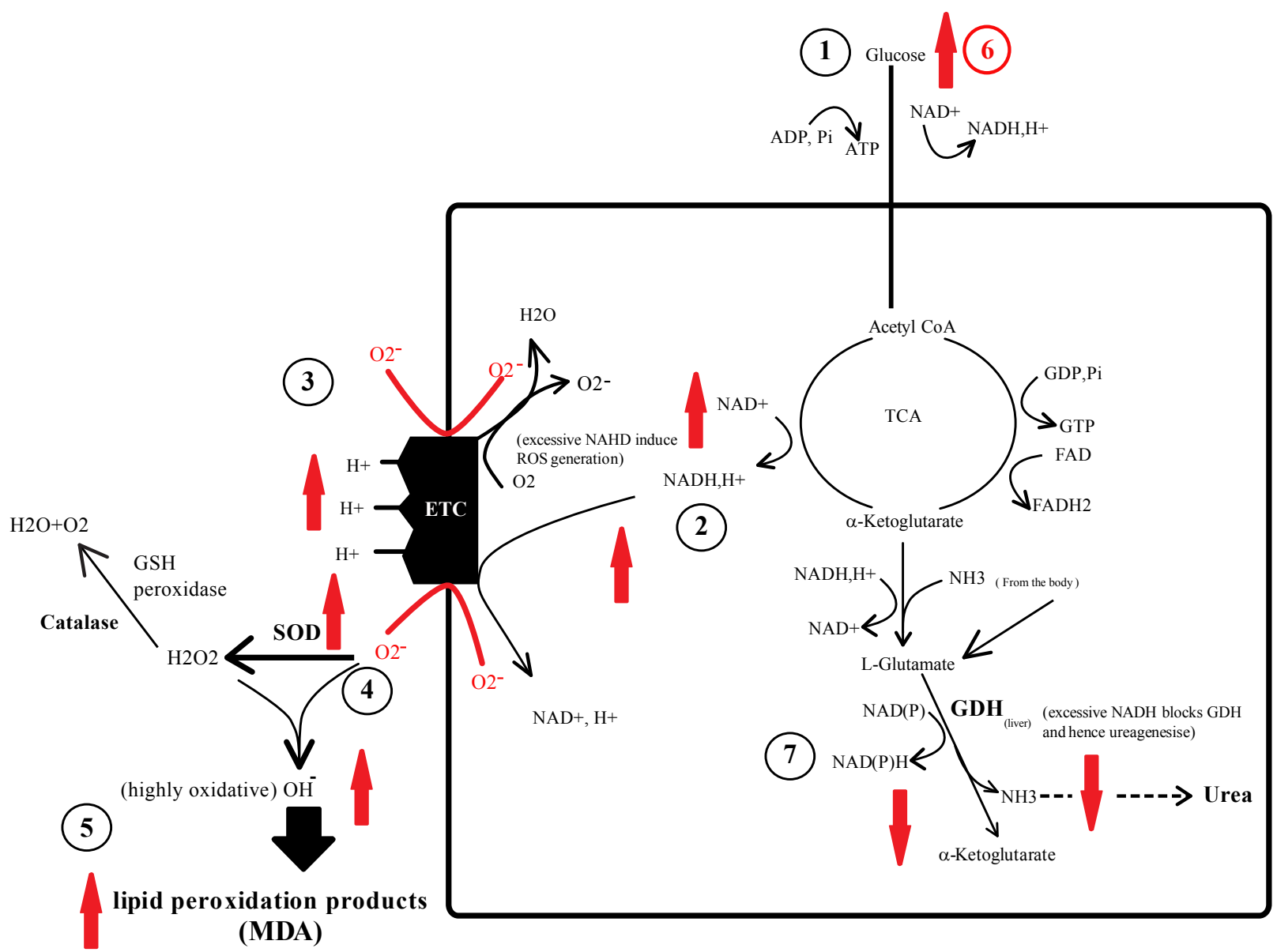

Figure 2: Effect of hyperglycemia on the production of reactive oxygen species and hepatic urea genesis.

1: Greater glucose oxidation and increased glucose uptake results into increased NADH and decreased NAD: NADH ratio.2: Increased NADH results into the hyperactivity of electron transport chain and consequently 3 : the generation of superoxide (O2-). 4: Superoxide dismutases (SOD) catalyze the dismutation of superoxide (O2-) into hydrogen peroxide. 5: abundant level of superoxide and hydrogen peroxide results into the generation of reactive oxygen species (ROS). Under normal conditions, ROS are cleared from the cell by the action of SOD, catalase, or glutathione peroxidase. 6: In hyperglycemia there is abundant level of NADH and ROS. The main damage to cells results from the ROS-induced alteration of macromolecules such as polyunsaturated fatty acids in membrane lipids. This results into the generation of malondialdehyde (MDA). Moreover SOD increased to protect cells against oxidative damage. Urea genesis decreases in hyperglycemia. 7: On the other hand release of ammonia from glutamate is catalyzed by the hepatic glutamate dehydrogenase (GDH), which is inhibited by NADH, ATP and GTP. Urea genesis results into $N A D(P)$ reduction This may explain the negative correlation between serum urea with markers of oxidative stress such as MDA and SOD in patients with type 2 diabetes.

TCA: Tricarboxylic acid cycle; ROS: reactive oxygen species; ETC: electron transport chain; GSH: glutathione; MDA: malondialdehyde; SOD: superoxide dismutase; $\mathrm{GDH}$ : glutamate dehydrogenase.

flux and protein synthesis increased less in type 2 diabetic men, during the hyperinsulinemic, glucose and amino acid clamp. They concluded that hyperglycemic men have insulin resistance of protein metabolism [43]. Theoretically it could be concluded that protein metabolism and urea formation is more influenced in diabetic men. Likewise insulin resistance increase markers of oxidative stress. This may partially explain the correlation between serum urea with MDA and SOD, only in men with type 2 diabetes. Future prospective studies, using larger trials investigating male/female differences or a trial to ascertain the impact of statin treatment upon these inflammatory markers would help to bolster the potential causation role of these inflammatory markers as culprits in the atherosclerotic process.

The principal limitation of the present study is its cross sectional nature. We did not measure the nitrogen balance; however diet was almost similar in composition in all the studied groups. Patients and controls were instructed to consume standardized meals that contained $50 \%$ carbohydrates, $30 \%$ fat and $20 \%$ protein, for two weeks before the beginning of the study. All the patients were consulted by a nutritionist during the study. On the other hand we took advantage of a relatively large sample size and close similarity between groups in most of the potentially confounding variables. In conclusion we showed the negative correlation between markers of oxidative stress and serum urea levels in men with type 2 diabetes. Though we cannot show the direction of causality, this finding paves the way for important future works aimed at determining the role of protein metabolism on markers of oxidative stress in patients with type 2 diabetes.

\section{References}

1. Moller N, Nair KS (2008) Diabetes and protein metabolism. Diabetes 57: 3-4 
2. Gougeon R, Pencharz PB, Sigal RJ (1997) Effect of glycemic control on the kinetics of whole-body protein metabolism in obese subjects with non-insulindependent diabetes mellitus during iso- and hypoenergetic feeding. Am J Clin Nutr 65: 861-870.

3. Gougeon R, Styhler K, Morais JA, Jones PJ, Marliss EB (2000) Effects of oral hypoglycemic agents and diet on protein metabolism in type 2 diabetes. Diabetes Care 23: 1-8

4. Luzi L, Petrides AS, De Fronzo RA (1993) Different sensitivity of glucose and amino acid metabolism to insulin in NIDDM. Diabetes 42: 1868-1877.

5. Tessari P (1994) Effects of insulin on whole-body and regional amino acid metabolism. Diabetes Metab Rev 10: 253-285.

6. Halvatsiotis PG, Turk D, Alzaid A, Dinneen S, Rizza RA, et al.(2002) Insulin effect on leucine kinetics in type 2 diabetes mellitus. Diabetes Nutr Metab 15 136-142.

7. Almdal TP, Petersen KF, Hansen BA, Vilstrup H (1986) Increased capacity of urea synthesis in streptozotocin diabetes in rats. Diabetologia 29: 812-816.

8. Almdal TP, Vilstrup H (1987) Effects of streptozotocin-induced diabetes and diet on nitrogen loss from organs and on the capacity of urea synthesis in rats. Diabetologia 30: 952-956.

9. Ahmed T, Rahman S, Cravioto A (2009) Oedematous malnutrition. Indian $J$ Med Res 130: 651-654

10. Bonatto F, Polydoro M, Andrades ME, da Frota Junior ML, Dal-Pizzol F, et al (2005) Effect of protein malnutrition on redox state of the hippocampus of rat Brain Res 1042: 17-22.

11. Calderon Guzman D, Espitia Vazquez I, Barragan Mejia G, Osnaya Brizuela N Hernandez Garcia E, et al. (2007) Effect of ivelip and sodium nitroprusside on $5-\mathrm{HT}$, glutathione and lipid peroxidation in normal and malnourished rat brain. Proc West Pharmacol Soc 50: 82-86.

12. Catal F, Avci A, Karadag A, Alioglu B, Avci Z (2007) Oxidant and antioxidant status of Turkish marasmic children: a single center study. J Trace Elem Med Biol 21: 108-112.

13. Becker K, Pons-Kuhnemann J, Fechner A, Funk M, Gromer S, et al. (2005) Effects of antioxidants on glutathione levels and clinical recovery from the malnutrition syndrome kwashiorkor--a pilot study. Redox Rep 10: 215-226.

14. Albrecht R, Pelissier MA (1995) About the oxidative stress status in children with kwashiorkor. Food Chem Toxicol 33: 1081-1083.

15. Toy H, Camuzcuoglu H, Arioz DT, Kurt S, Celik H, et al. (2009) Serum prolidase activity and oxidative stress markers in pregnancies with intrauterine growth restricted infants. J Obstet Gynaecol Res 35: 1047-1053.

16. Raab EL, Vuguin PM, Stoffers DA, Simmons RA (2009) Neonatal exendin-4 treatment reduces oxidative stress and prevents hepatic insulin resistance in intrauterine growth-retarded rats. Am J Physiol Regul Integr Comp Physiol 297 R1785-1794.

17. Kahn CR (1994) Banting Lecture. Insulin action, diabetogenes, and the cause of type II diabetes. Diabetes 43: 1066-1084.

18. Paolisso G, Giugliano D (1996) Oxidative stress and insulin action: is there a relationship? Diabetologia 39: 357-363.

19. Rudich A, Kozlovsky N, Potashnik R, Bashan N (1997) Oxidant stress reduces insulin responsiveness in 3T3-L1 adipocytes. Am J Physiol 272: E935-940.

20. Sies H (1991) Oxidative stress: from basic research to clinical application. Am J Med 91: 31S-38S.

21. Giacco F, Brownlee M (2010) Oxidative stress and diabetic complications. Circ Res 107: 1058-1070.

22. Nakhjavani M, Esteghamati A, Nowroozi S, Asgarani F, Rashidi A, et al. (2010) Type 2 diabetes mellitus duration: an independent predictor of serum malondialdehyde levels. Singapore Med J 51: 582-585.

23. West IC (2000) Radicals and oxidative stress in diabetes. Diabet Med 17: 171 180.

24. American Diabetes Association (2004) Diagnosis and Classification of Diabetes Mellitus. Diabetes Care 27: S5-S10.

25. Cockcroft DW, Gault MH (1976) Prediction of creatinine clearance from serum creatinine. Nephron 16: 31-41.

26. Nissim I, Cattano C, Nissim I, Yudkoff M (1992) Relative role of the glutaminase glutamate dehydrogenase, and AMP-deaminase pathways in hepatic ureagenesis: studies with 15N. Arch Biochem Biophys 292: 393-401.

27. Carracedo J, Merino A, Briceno C, Soriano S, Buendia P, et al. (2011) Carbamylated low-density lipoprotein induces oxidative stress and accelerated senescence in human endothelial progenitor cells. FASEB J 25: 1314-1322.

28. Chen Y, Yi L, Yan GQ, Jang YX, Fang YW, et al. (2010) Decreased chaperone activity of alpha-crystallins in naphthalene-induced cataract possibly results from C-terminal truncation. J Int Med Res 38: 1016-1028.

29. Lehninger AL (1964) The Transfer of Energy in Oxidative Phosphorylation. Bul Soc Chim Biol 46: 1555-1575.

30. Griffiths DE (1965) Oxidative phosphorylation. Essays Biochem 1: 91-120.

31. Brownlee M (2005) The pathobiology of diabetic complications: a unifying mechanism. Diabetes 54: 1615-1625.

32. Stumpf DA, Parks JK (1980) Urea cycle regulation: I. Coupling of ornithine metabolism to mitochondrial oxidative phosphorylation. Neurology 30: 178-183.

33. Murray RK, Granner DK, Mayes PA, Rodwell V (2003) W. Harper's Illustrated Biochemistry. (26th edn.), McGraw-Hill.

34. Meijer AJ, Gimpel JA, Deleeuw G, Tischler ME, Tager JM, et al. (1978) Interrelationships between gluconeogenesis and ureogenesis in isolated hepatocytes. J Biol Chem 253: 2308-2320.

35. Medvedeva NB, Telushkin PL, Stel'makh AY (2008) Parameters of nitrogen metabolism during insulin hypoglycemia in rats with alloxan-induced diabetes. Bull Exp Biol Med 146: 203-205.

36. Brownlee M (2005) The pathobiology of diabetic complications: a unifying mechanism. Diabetes 54: 1615-1625.

37. Dasarathy S, Kasumov T, Edmison JM, Gruca LL, Bennett C, et al. (2009) Glycine and urea kinetics in nonalcoholic steatohepatitis in human: effect of intralipid infusion. Am J Physiol Gastrointest Liver Physiol 297: G567-575.

38. Anderson EJ, Kypson AP, Rodriguez E, Anderson CA, Lehr EJ, et al. (2009) Substrate-specific derangements in mitochondrial metabolism and redox balance in the atrium of the type 2 diabetic human heart. J Am Coll Cardiol 54 1891-1898.

39. Asmann YW, Stump CS, Short KR, Coenen-Schimke JM, Guo Z, et al. (2006) Skeletal muscle mitochondrial functions, mitochondrial DNA copy numbers, and gene transcript profiles in type 2 diabetic and nondiabetic subjects at equal levels of low or high insulin and euglycemia. Diabetes 55: 3309-3319.

40. Stump CS, Short KR, Bigelow ML, Schimke JM, Nair KS (2003) Effect of insulin on human skeletal muscle mitochondrial ATP production, protein synthesis, and mRNA transcripts. Proc Natl Acad Sci U S A 100: 7996-8001.

41. Chevalier S, Marliss EB, Morais JA, Lamarche M, Gougeon R (2005) The influence of sex on the protein anabolic response to insulin. Metabolism 54 1529-1535.

42. Gougeon R, Morais JA, Chevalier S, Pereira S, Lamarche M, et al. (2008) Determinants of whole-body protein metabolism in subjects with and without type 2 diabetes. Diabetes Care 31: 128-133.

43. Pereira S, Marliss EB, Morais JA, Chevalier S, Gougeon R (2008) Insulin resistance of protein metabolism in type 2 diabetes. Diabetes 57: 56-63. 